\title{
JUDICIALIZAÇÃo DA POLÍTICA E DAS RELAÇÕES SOCIAIS EM REVISTA: a Constituição cidadã e a modernização da tradição
}

\author{
JUDICIALIZATION OF POLITICS AND SOCIAL RELATIONS IN INSPECT: the citizenship \\ constitution and the modernization of tradition
}

\author{
Paulo G. S. Périssé \\ PUC Rio
}

\section{Resumo:}

O transcurso dos trinta e dois anos da publicação da Constituição Federal permite uma análise retrospectiva do cenário dentro do qual desenvolveu-se o processo de judicialização da política e das relações sociais no Brasil. Neste artigo, pretende-se explorar o processo de judicialização das relações de trabalho que antecede ao período de vigência da Constituição Federal de 1988 e seus fortes vínculos com o processo de modernização brasileiro. Nessa perspectiva, sustenta-se que, a partir dos anos 1930, o sistema jurídico laboral teria sido instrumentalizado para atuar como um dos pilares de uma renovada articulação entre a vida social e os sistemas econômico e político. Por outro lado, destaca-se como tal arranjo teria sido funcional para a preservação dos interesses hegemônicos e a chamada "modernização da tradição", conceito que estrutura o argumento. A hipótese é de que a estratégia da judicialização, rearticulada desde os anos 1980, encontrou seus limites ao replicar o deslocamento para o campo jurídico e defini-lo como espaço privilegiado para fazer avançar o projeto político inscrito no texto constitucional.

\section{Palavras-chave:}

Judicialização. Relações de trabalho. Modernização da tradição.

\begin{abstract}
:
It's been thirty-one years since the publication of the Federal Constitution. That allows for a retrospective analysis of the scenario in which the process of judicialization of politics and social relations in Brazil developed. This article intends to explore the process of judicialization of labor relations preceding the Federal Constitution of 1988 and its strong links with the Brazilian process of modernization. Accordingly with this perspective, it is maintained that, from the 1930s, the labor legal system would have been instrumentalized to act as one of the pillars of a renewed articulation between social life and the economic and political systems. On the other hand, it stands out how such an arrangement would have been functional for the preservation of hegemonic interests and the so-called "modernization of tradition", a concept that underpins the argument. The hypothesis is that the judicialization strategy, rearticulated since the 1980s, has found its limits by replicating the displacement to the legal field and defining it as a privileged spherewhere the political project inscribed in the constitutional text could be advanced.
\end{abstract}

\section{Keywords:}

Judicialization. Labor relations. Modernization of tradition 


\section{INTRODUÇÃO}

O cenário ampliado da chamada judicialização da política e das relações sociais tem contemplado abordagens polarizadas por parte da teoria social brasileira que, em linhas muito gerais, oscila entre o afirmado aspecto virtuoso desse processo, visto como o alargamento da democracia brasileira, ao lado de outra vertente que lhe é oposta por sustentar que tal processo reproduz uma longa tradição de intervenção do Estado na esfera pública, com o propósito de sufocar e controlar a livre movimentação dos atores sociais ${ }^{1}$.

Ao longo dos últimos anos, desde a publicação da Constituição Federal, diversas agendas de pesquisa procuraram captar como o protagonismo assumido pelo sistema judicial teria contribuído ou não para o aprofundamento da democracia brasileira. De certa forma, o campo jurídico, embora nem sempre de modo sistematizado, repercutia os diagnósticos construídos pela teoria social.

Sob o ponto de vista normativo, o que se pretende recuperar é o processo de judicialização que antecede a 1988 e que foi determinante para a estruturação do Direito do Trabalho brasileiro nos anos 1930 e 1940. Esse movimento, contemporâneo do processo de modernização brasileiro, colocou o sistema jurídico como um dos pilares de uma renovada articulação entre a vida social e os sistemas econômico e político.

Nessa trajetória, o Estado e suas instituições teriam assumido o papel-chave de integração e criação de solidariedade sociais, valendo-se, no ponto investigado, do controle e da coordenação da ação coletiva dos trabalhadores. A estratégia empregada envolveu a criação de um sistema normativo funcional e o deslocamento para o sistema judicial das eventuais disputas envolvendo trabalhadores e empregadores. Dessa forma, ao procurar sufocar as disputas abertas no mercado, essa estratégia pretendia limitar seus efeitos disruptivos, especialmente porque os episódios do início do século XX em cidades como Rio de Janeiro e São Paulo já haviam revelado o quanto o sistema da ordem vigente poderia ser abalado, com a movimentação livre dos trabalhadores por melhores condições de existência e participação política².

A despeito dos cenários e circunstâncias distintos que separam essas transformações ocorridas nos anos 1930 e 1980, vale observar como a mobilização do sistema judicial foi

\footnotetext{
${ }^{1}$ Exemplo dessas visões distintas estão em Werneck Vianna et al (1999; 2002), Maciel e Koerner (2002) e Arantes (1997; 1999).

${ }^{2}$ Uma evidência dessa trajetória foi explorada por Gomes (2005).
} 
manobrada pelas forças políticas hegemônicas e com que propósitos, nem sempre explicitados, é bem verdade, mas direcionados a fazer prevalecer agendas e interesses muito próprios.

A proposta aqui será identificar os argumentos que justificaram o caminho da judicialização das relações de trabalho e compará-los àqueles manobrados desde a retomada da democracia nos anos 1980. A percepção de que esses processos, separados por contextos tão distintos, envolveram bases argumentativas e estratégias similares, pode sugerir uma dimensão não abordada da judicialização recente, ou seja, sua articulação com a chamada “modernização da tradição”, conceito-chave com o qual se pretende explorar esse tema.

Ao final, espera-se sinalizar como a estratégia da judicialização pode ser articulada ao processo maior de preservação dos interesses hegemônicos dentro da "alta modernidade brasileira"3, mesmo quando expurgados os elementos autoritários com os quais operava o sistema político.

\section{A JUDICIALIZAÇÃO EM PERSPECTIVA}

O tema da judicialização não estava posto aos constituintes de 1988, embora não fosse desconhecido no universo dos juristas que atuavam nos bastidores, como consultores das lideranças políticas. O renovado papel do sistema judicial nas democracias modernas que emergiram do segundo pós-guerra, especialmente na Europa, era tema debatido na literatura jurídica. Por essa razão, pretende-se resgatar, inicialmente, essa trajetória percorrida pelo sistema judicial.

De fato, ao longo do século XX, o papel do sistema judicial passou por uma profunda transformação caracterizada por sua progressiva intervenção na esfera pública como mecanismo eficiente para assegurar o funcionamento das democracias do pós-guerra, ainda profundamente marcadas por um conflito trágico e revelador dos limites do sistema político fortemente baseado na vontade das maiorias parlamentares.

Nesse sentido, pode-se dizer que a judicialização emergiu como corolário da reformulação dos sistemas de pensamento que ampararam as democracias ocidentais, cujos pactos políticos renovados deixaram ao sistema judicial o papel de explicitar o sistema de

\footnotetext{
${ }^{3}$ Domingues (2002) explora o conceito de modernidade avançada ou "alta modernidade brasileira" para recusar o valor explicativo de uma modernização ocidental uniforme e acentuar suas várias faces no cenário local.
} 
valores e princípios sobre os quais passaram a fundar-se. No plano teórico, o chamado neoconstitucionalismo ou constitucionalismo democrático do pós-guerra pode ser percebido como sinal desse papel do direito, agora vocacionado a concretizar os sistemas de princípios e valores inscritos nas constituições modernas.

Em paralelo, vale lembrar, dentro de um processo ampliado de demandas direcionadas ao Estado, a própria vida social foi alcançada por essa projeção do Direito como vertebrador dos processos de interação, dentro da dinâmica da chamada juridificação ${ }^{4}$.

No Brasil, apenas nos anos 1980, esses movimentos ganharam dimensão, dentro do processo de redemocratização. O conceito de judicialização, por sua vez, somente nos anos 1990 começou a ser manobrado pela literatura do campo social a partir da incorporação do trabalho seminal organizado por Tate e Vallinder (1995). Por outro lado, vale recordar que essa tendência, ainda que não sistematizada, já havia sido identificada pela teoria jurídica ao abordar o tema geral do acesso à justiça, o que repercutiu no cenário democrático brasileiro, em gestação (CAPPELLETTI; GARTH, 1988).

Portanto, importa reter desde já que, seja do ponto de vista da teoria social como da teoria jurídica, o horizonte de mudanças dos anos 1980 já anunciava a reformulação do papel do Direito dentro do sistema democrático brasileiro, ecoando as grandes transformações empreendidas alhures.

Entretanto, a articulação dessas abordagens com o processo de construção e institucionalização do Direito do Trabalho brasileiro revela-se fundamental para compreender o sentido da integração dessa estratégia no nosso universo. Isso porque, como será abordado em seguida, a ideia de concretizar um sistema de direitos estava no vértice do processo de judicialização das relações de trabalho em curso no Brasil, desde a intensificação do processo de modernização no período Vargas.

Para compreender esse movimento antecedente, contudo, dois aspectos são relevantes. Em primeiro lugar, o Direito passou por uma profunda reformulação dos seus postulados clássicos, superando a perspectiva do contrato como esfera imune à interferência do Estado. Uma tal renovação na compreensão e justificativa do Direito foi a base para a entrada em cena

\footnotetext{
4 Vale observar que dentro desse cenário convergem dois fenômenos distintos: a judicialização e a juridificação. Por um lado, a judicialização reflete a expansão da atuação do sistema judicial fora dos limites tradicionais estabelecidos no receituário do liberalismo clássico, como resposta aos imperativos do próprio sistema político. Por outro, um fenômeno correlato, mais profundo e, pode-se dizer, constitutivo desse movimento, a chamada juridificação da vida social típica da fase de ampliação da intervenção do Estado, dentro da qual o Direito assumiu papel instrumental.
} 
de um novo ramo, o Direito do Trabalho. O segundo aspecto implica a exploração do papel singular desempenhado pelo Direito do Trabalho dentro do processo da chamada modernização conservadora que marcou o cenário brasileiro.

\section{A SUPERAÇÃO DOS FUNDAMENTOS DO DIREITO LIBERAL CLÁSSICO: A MATERIALIZAÇÃO DO DIREITO}

O processo de modernização brasileiro dos anos 1930 transformou por completo os referenciais sobre os quais estava estruturado o pacto político, social e econômico que amparava o sistema de ordem da chamada República Velha. Nessa guinada, a compreensão do direito passou por profunda revisão. Essa inflexão está associada ao amplo processo de modernização ocidental dentro do qual sociedades periféricas estão incluídas com suas próprias dinâmicas.

Um pressuposto desse movimento no campo jurídico consistiu justamente na superação dos fundamentos clássicos do Direito Liberal, para justificar a intervenção do Estado relações socioeconômicas, fenômeno que marcou o século XX e exigiu uma reinterpretação do papel a ser desempenhado pelo direito nas sociedades democráticas ocidentais.

Com efeito, na sua configuração clássica, o Direito Liberal foi estruturado a partir da premissa básica de que a participação de indivíduos livres e formalmente iguais no mercado bastaria para estabelecer relações de troca justas e distribuir com equilíbrio a riqueza socialmente produzida. O equilíbrio teria relação com a preponderância dos mais capazes, sem considerações acerca dos limites de ação efetivos daqueles tomados por formalmente iguais. O Direito fechava os olhos às considerações de ordem material, mesmo porque a ideologia do mercado justificava essa abstenção.

A emergência da questão social ao longo do século XIX transformou completamente a forma de compreensão do Direito e colocou o desafio de incorporar à sua dinâmica o tema da materialização, de fato, das promessas inscritas na lei. Seu caráter abstrato vinha agora acompanhado da necessidade de efetividade, expressão com a qual se vislumbrava a centralidade assumida pela concretização dos ideais de liberdade e igualdade que sustentavam o horizonte normativo. 
Esse processo de materialização do Direito ${ }^{5}$ teria, assim, íntima ligação com o Direito do Trabalho, ramo onde repercutiu a questão social e que estabeleceu um novo padrão normativo agora direcionado para estabelecer critérios de justiça no âmbito das relações de mercado. Tal abertura do Direito, ainda que envolvesse riscos para sua própria integridade, foi a porta de entrada da subjetividade ou da criatividade como elemento com o qual seus operadores passariam a lidar.

Numa limitada recuperação das etapas desse largo processo, pode-se afirmar que o direito do Estado Social, que emergiu nas democracias centrais tinha como forte característica a materialização crescente e a sujeição da autonomia privada a critérios morais de justiça. Dentro dessa ordem político-social, a intervenção do Estado e seu aparato burocrático foram preponderantes e deixaram de ser percebidas como disfuncionais ao funcionamento do mercado.

No campo jurídico, o sentido dessa mudança seria sinalizado, por exemplo, com a revolta contra o formalismo jurídico ou contra o positivismo jurídico, por meio da crítica explícita ao modelo lógico-formal que orientava o processo decisório no modelo liberal clássico e que limitava qualquer ação criativa dos aplicadores da norma (CAPPELLETTI, 1993).

$\mathrm{O}$ que dramatizou esse quadro num segundo momento e, de certo modo explicaria a mudança posterior, foi a inadequação do aparato estatal para lidar com o largo processo de complexificação da vida social. Sob o Welfare State, o poder regulatório do Estado foi expandido e invadiu a vida social. Como consequência, a legislação assumiu um caráter promocional e delegou para outras esferas institucionais, como agências ou comitês, a tarefa de tornar efetivos princípios e finalidades inscritas na legislação. Os direitos sociais, como aqueles que lidavam com o tema do trabalho, exigiam a intervenção ativa do Estado.

Entretanto, no momento subsequente, a sobrecarga das agências encarregadas de tornar efetivos os direitos sociais e sua incapacidade de atender ao crescente volume das demandas formaram o pano de fundo para a integração do sistema judicial nesse processo. Alheio, num primeiro momento, ao Judiciário passam a ser canalizadas demandas e expectativas de um novo tipo. O segundo pós-guerra marca o crescente avanço do sistema judicial sobre a vida social, processo que certamente não era imune aos riscos de perversão e abuso (CAPPELLETTI, 1993).

\footnotetext{
${ }^{5}$ Uma interessante crítica ao clássico argumento weberiano em torno da materialização do direito pode ser encontrada em Habermas (2003).
} 
Essa reconfiguração do papel do Direito e do sistema judicial na organização da vida moderna ganhou dramaticidade com o fenômeno do constitucionalismo e da massificação dos conflitos sociais. Nesse sentido, mecanismos de controle inscritos em textos políticos transferiram ao sistema judicial a tarefa de interpretar o sentido dos valores morais compartilhados pelas comunidades políticas. Tal estratégia envolveu a criação de normas abertas amparadas em princípios e normas gerais que permitiam ao intérprete operar com altas doses de discricionariedade para determinar-lhes o sentido e o alcance (CITTADINO, 1999).

Nesse cenário, ganharam dimensão novos temas, como o acesso à Justiça, e novas ferramentas destinadas a concretizar o sistema de direitos e dar vazão às pressões de grupos organizados da sociedade.

A reconstrução por etapas desse largo processo de materialização do Direito, contraditório e nem sempre linear, apesar de suas limitações, é funcional para deixar entrever, no caso brasileiro, como o surgimento e a institucionalização do Direito do Trabalho exigiu novas formas de justificação do Direito, sem que com isso fossem abandonados os postulados liberais que lhe davam sustentação ${ }^{6}$.

Nessa mesma mirada, já pode-se especular o sentido da reconfiguração do Direito Constitucional, na chamada alta modernidade brasileira (DOMINGUES, 2004), com a institucionalização do constitucionalismo democrático a partir do final dos anos 1980 e sua pretensão de efetividade.

De qualquer forma, procurando sintetizar esse esquema, esses dois momentos de inflexão implicaram a incorporação de novos paradigmas no sistema jurídico brasileiro, combinando influxos externos e a necessidade de dar conta de um sistema da ordem pressionado por democratizar-se, desde sempre, por impulso de um liberalismo cambiante, como se pretende recuperar em seguida.

\section{MOdERNIZAÇÃO CONSERVADORA DOS ANOS 1930 NO BRASIL E O PAPEL DO DIREITO DO TRABALHO}

\footnotetext{
${ }^{6}$ No clássico estudo sobre a instauração da ordem liberal no Brasil e sua articulação com os grupos sociais subalternos, especialmente aqueles ligados ao movimento sindical, Werneck Vianna (1978) também já chamava a atenção para a importância de um esquema analítico que recuperasse a centralidade dos postulados liberais porque os processos de mudança dos sistemas de ordem, desde a superação da ortodoxia liberal, não implicaram em derrogação dos seus princípios de estruturação.
} 
Como registrado acima, os anos 1930 evidenciam uma grande inflexão do sistema jurídico brasileiro quando seus fundamentos foram confrontados com novas formas de justificativa reivindicadas pelo novo ramo, o Direito do Trabalho.

O pano de fundo desse processo, entretanto, foge aos limites do Direito, razão por que vale resgatar nessa trajetória a perspectiva do enfrentamento da chamada questão social que convulsionava o sistema político, ainda fundado no agrarismo da República Velha.

De fato, em retrospectiva, o enfrentamento da questão social, foi um dos grandes dilemas no campo político dentro do período pré-1930, quando as elites agrárias recusavam seu enfrentamento, negando sua existência e recorrendo à repressão como padrão de ação. Portanto, negação e repressão foram suas estratégias desde o momento em que emergiu o tema no final do século XIX até a Revolução de 1930, quando passou a integrar a agenda do Estado.

A pressão dos movimentos organizados dos trabalhadores, especialmente a partir da virada do século, garantiu algumas conquistas esparsas cujo sentido prático foi conduzir o Estado a timidamente reconhecer o problema e criar alguns marcos regulatórios para o trabalho assalariado que emergia, principalmente, nos grandes centros urbanos.

Como observa Delgado (2016), no período desde 1888 até 1930, o movimento operário, ainda sem organização suficiente para determinar a construção de práticas e resultados normativos consistentes, obteve, contudo, no plano legislativo, o enfrentamento tímido e assistemático da questão social, já que o predomínio dos postulados liberais era evidente.

De qualquer forma, ainda que incipientes, as conquistas alcançadas nesse cenário adverso já sinalizavam a posição estratégica assumida pelo Direito, instrumento central para sedimentar as eventuais soluções extraídas do embate político.

Entretanto, ainda predominava no plano sociopolítico, como regra geral, a vedação da ação política autônoma dos trabalhadores e a restrição à criação de mecanismos de regulação e proteção do nascente trabalho fabril.

O problema consistia, de um lado, na pressão por incorporação de estratos dos movimentos organizados dos trabalhadores pela ação do Estado por meio dos temas sensíveis da chamada questão social e, de outro, na existência de uma estrutura jurídica formatada a partir do modelo liberal clássico, dentro do qual tal intervenção era inaceitável. Essa gangorra perdura até 1930 sem que alguma redefinição da estrutura jurídica tenha permitido abandonar 
as trincheiras da clássica visão do Direito Liberal, centrado na ideia de liberdade formal e não intervencionismo estatal ${ }^{7}$.

A solução do dilema político em 1930 viria acompanhada de um novo paradigma jurídico justamente para dar conta dessa realidade adversa e sempre ameaçadora da ordem vigente, cuja hegemonia, nesse ponto, foi conseguida à custa de soluções de compromisso que envolveram até mesmo as decadentes elites agrárias.

Do ponto de vista jurídico, apesar de manifestações esparsas de alguns juristas ${ }^{8}$, apenas com a eclosão e a vitória dos revolucionários de 1930 é que efetivamente o Estado incorpora o problema e passa a enfrentá-lo com as ferramentas do Direito e suas instituições.

Mas, para avançar nessa perspectiva, toda forma de lidar com o arcabouço legal seria reorientada e seus práticos deveriam abandonar seus antigos dogmas. Essa transformação não seria simples e demandaria um longo período de maturação.

Como se percebe nessa trajetória, a influência do contexto nas formas de perceber, interpretar e aplicar o Direito é um elemento-chave para entender-se a mudança. No caso brasileiro, é relevante observar como a movimentação dos trabalhadores por incorporação no plano político e por melhoria de suas próprias condições de existência formou o elemento indutor da reformulação do estatuto legal laboral.

Um dos episódios marcantes que evidencia essa transformação no campo jurídico envolveu o clássico embate entre Oliveira Vianna e Waldemar Ferreira, juristas prestigiados e com visões antagônicas sobre o papel do Estado e sua relação com o mercado, como recordou Lafer (1999).

Pode-se observar, nesse ponto, como o projeto político hegemônico seria alinhado ao Direito, cujo papel renovado, através da incorporação de um novo ramo, atuaria como fio condutor da mudança.

De certa forma, sob outro ângulo, o tema da materialização sobressaía nesse cenário e a publicização do Direito (LAFER,1999) teria esse caráter instrumental. Nesse sentido, a dogmática jurídica tradicional, arraigada no indivíduo, na abstração das normas jurídicas e no racionalismo técnico jurídico, estava dissociada dessas exigências de maior protagonismo estatal.

\footnotetext{
${ }^{7}$ Ordem liberal, de certo tipo, limitada a aspectos pontuais, por certo.

${ }^{8}$ Como a surpreendente inflexão de Rui Barbosa manifestada na conferência pronunciada em março de 1919, no Teatro Lírico, no Rio de Janeiro. Disponível em: http://www.casaruibarbosa.gov.br/dados/DOC/artigos/rui_barbosa/p_a5.pdf. Acesso em 01/02/2019.
} 
O que estava em jogo, portanto, era a abertura do Direito e a superação das abstrações contidas nas normas jurídicas, uma vez que estava autorizada a intervenção direta do Estado e seus agentes em relações jurídicas até então imunes ao seu poder.

O desenrolar dos acontecimentos a partir de 1937 conduziu ao centralismo político com a instauração da ditadura de Vargas e a consolidação de um projeto desenvolvimentista conduzido a partir do Estado, recorrendo ao nascente Direito do Trabalho e suas ferramentas como instrumentos da mudança em curso. O Direito do Trabalho assumiria um papel central, como um dos fiadores dessa transformação (WERNECK VIANNA, 2002).

O processo de modernização brasileiro define-se, assim, por seu conteúdo conservador forjado por um arranjo que envolvia conciliação dos interesses das elites, agora posicionadas no interior do Estado, cujo papel de condução e controle dos diversos interesses em disputa sobressaía.

Esse processo ambíguo repercutiu no Direito do Trabalho, conferindo-lhe uma dupla face. De um lado, representava um avanço em termos de reivindicações históricas dos movimentos organizados dos trabalhadores, agora codificadas e implementadas seletivamente. Por outro, esse ganho se daria à custa do controle da sua ação coletiva por parte da burocracia estatal.

O fato relevante nesse ponto, portanto, é observar que romper com a ortodoxia liberal naquele cenário não implicava a reformulação profunda do Direito, senão dentro dos limites instrumentais ao poder político. Se a proposta era a modernização sob controle do Estado, o Direito do Trabalho, especialmente o Direito Coletivo do Trabalho e seus instrumentos de ação, ainda que implicassem a superação do individualismo do Direito Civil, também estariam contidos nas fronteiras desse arranjo.

Ao final da primeira Era Vargas, com a retomada do processo democrático e a institucionalização do Direito do Trabalho brasileiro entra em cena a estratégia da judicialização das relações do trabalho, com a criação da Justiça do Trabalho e sua integração ao Poder Judiciário, ponto a ser abordado a seguir.

\section{JUDICIALIZAÇÃO DAS RELAÇÕES DE TRABALHO: ESTRATÉGIA DE AÇÃO}

Como já sinalizado, sob o ângulo das relações coletivas de trabalho, o modelo normativo a partir do qual foi montada nossa estrutura sindical tinha estreita ligação com o processo de modernização brasileiro. 
O que a literatura convencionou chamar "modernização pelo alto" ou "modernização conservadora" (WERNECK VIANNA, 1978) tem relação com uma intrincada teia de interesses sustentada pela homogeneização das elites político-econômicas construída ao longo do primeiro período Vargas. Foi no embate entre as forças políticas que emergiram da Revolução de 1930 que definições e compromissos se estabeleceram para colocar tanto a sociedade como a própria política a serviço da expansão econômica.

Isso se deu, especificamente, no plano das relações coletivas dos trabalhadores, à custa da supressão de qualquer ação autônoma de seus movimentos organizados, com sua ação estruturada e mediada pelo Estado e seus órgãos de controle ${ }^{9}$. Nesse momento, o Estado é o articulador dos acordos políticos entre as elites hegemônicas e o promotor do desenvolvimento econômico. Ancorado na ideologia da harmonia entre o capital e o trabalho como forma de amortecimento e encapsulamento dos interesses, ao mesmo tempo transfere para suas estruturas burocráticas o conflito entre as forças antagônicas do mercado. No plano das relações contratuais no mercado de trabalho, é a lei quem detém a primazia na ideologia da paz social e da harmonia ${ }^{10}$.

O Direito, e o Direito do Trabalho em particular, é o instrumento com o qual opera o sistema político na difusão dessa ideologia e controle do conflito, na tentativa de impedir o confronto aberto no mercado, ainda potencialmente disruptivo naquele contexto.

Nesse cenário, o sistema judicial, com a regulamentação da Justiça do Trabalho em $1939^{11}$, emergiu como instrumento fundamental para efetivar essa ideologia no âmbito das relações coletivas.

Como ferramenta de ação, teria o poder de prolatar sentenças normativas com as quais decidiria essa espécie de conflito, criando normas às quais estariam obrigadas as partes interessadas. O chamado poder normativo, assim, teria o sentido de incorporar critérios de justiça elaborados pelo campo jurídico, no âmbito das relações coletivas de trabalho. Em suma, convertia-se a disputa mercantil entre o capital e a força de trabalho num fato jurídico, tratado segundo os cânones do direito (WERNECK VIANNA, 1978).

\footnotetext{
${ }^{9}$ Nesse período, que vai de 1939, quando criada a legislação sindical, até 1946, com a deposição de Vargas, Cardoso (2003), por exemplo, identifica a vigência plena do corporativismo no Brasil.

10 Propósito revelado na própria exposição de motivos da CLT: “ 29. A análise do conteúdo da nossa legislação social prova exuberantemente a primazia do caráter institucional sobre o efeito do contrato, restrito à objetivação do ajuste, à determinação do salário e à estipulação da natureza dos serviços e isso mesmo dentro de standards e sob condições preestabelecidas na lei." Disponível em: http://aplicacao.tst.jus.br/dspace/bitstream/handle/1939/29280/1943_clt_exposicao_motivo.pdf?sequence= 1. Acesso em 17/09/2019.

${ }^{11}$ Por meio do Decreto-lei 1.237/1939.
} 
Essa conversão do conflito mercantil em conflito jurídico marca, portanto, a entrada do sistema judicial no âmbito das relações coletivas de trabalho. Ainda que a Justiça do Trabalho somente em 1946 passasse a fazer parte formalmente da estrutura do Poder Judiciário, a ferramenta do poder normativo para a solução de conflitos coletivos de trabalho lhe é antecedente. O dissídio coletivo era a categoria jurídica que ordenava o conflito não solucionado no mercado e canalizado para o campo do Direito. Pode-se entrever que caberia à Justiça o papel de direção consciente do mercado, vertendo as relações mercantis entre o capital e o trabalho para a linguagem normativa do direito (WERNECK VIANNA,1978). A harmonia idealizada pelo regime seria alcançada com essa intervenção, pode-se dizer lateral, do Estado ao mediar o conflito através da Justiça do Trabalho sob o manto da neutralidade e da impessoalidade das regras do Direito.

O processo de materialização do Direito, do qual o Direito Laboral é corolário, ganha sentido próprio nesse movimento, como será explorado melhor adiante.

A Justiça do Trabalho pode ser percebida, assim, como um "subsistema funcional convergindo para o fim maior de subtrair o litígio do mercado, tendendo a eliminar ou reduzir o caráter político na movimentação orgânica das classes subalternas" (WERNECK VIANNA,1978, p.240). Esse arcabouço jurídico, do qual fazem parte a CLT e a própria Justiça, tinha como suposto para seu funcionamento a asfixia e a submissão dos interesses e exigia, ainda, um sindicalismo dócil ao modelo corporativo e disposto a canalizar suas disputas na direção do canal institucional vocacionado para dizer o justo pela linguagem do Direito.

Percebe-se, portanto, que a lei assume papel preponderante na regulação do mercado e o sistema judicial é funcional para esse propósito. Dizer o Direito ao solucionar os conflitos coletivos através do poder normativo tinha o duplo sentido de, por um lado, suprimir o conflito aberto no mercado e, por outro, construir a ideia do justo a partir do Direito.

A validade desse desenho é reafirmada mesmo quando superada a ordem corporativa em 1946, ocasião na qual, a despeito da incorporação formal da Justiça do Trabalho ao sistema judicial, foi mantida sua característica principal de conversão do conflito coletivo na categoria jurídica de dissídio. Manteve-se, portanto, o poder de criar regra a qual é imposta às partes sob o discurso do Direito através do chamado poder normativo.

Nesse sentido, a judicialização das relações de trabalho, no Brasil, não deve ser compreendida sem incorporar a série de interações desenvolvidas até aqui. 
De um lado, um projeto político desenvolvimentista foi sendo consolidado ao longo dos anos 1930 e envolvia a admissão, sob tutela, das classes subalternas na cena pública. O papel ordenador do Estado prevalece sobre o ambiente social e o controle do movimento sindical é sua face visível.

No campo jurídico, porque o Direito é a forma eficiente de estabelecer formas de coesão social e de legitimação do poder, se estabelece um novo marco teórico que admite o conflito social e professa sua solução "justa", através de uma racionalidade técnica operada por uma elite intelectual.

Ao final do primeiro período Vargas, o modelo legislado de organização das relações de trabalho (NORONHA, 2000) se estabelece como a principal forma de articulação entre trabalhadores e empregadores, agora hábeis no manuseio de normas e regulamentos.

O fato é que, sob o controle das elites da burocracia estatal, aliadas aos interesses políticos e econômicos hegemônicos a judicialização das relações de trabalho esteve na base do processo de modernização brasileiro cumprindo o papel de contenção de um de seus principais atores, os trabalhadores ${ }^{12}$. O sistema da ordem vigente, após anos de embates admitia a incorporação dos trabalhadores ao custo de sua contenção e controle.

A transferência do conflito coletivo para o sistema judicial revelou-se estratégica e funcional naquele momento, com o desenvolvimento econômico ancorado na contenção das reivindicações organizadas dos trabalhadores. Essa ambivalência, ou seja, ganho de direitos sob certos limites, tinha o sistema judicial como coordenador. Canalizar as disputas ao sistema judicial seria funcional ao modelo democrático dos anos 1946 - 1964, a tal ponto que não chegaria a ser surpresa, embora paradoxal, que o aparato de intervenção judicial somente após a segunda Era Vargas, de fato, tenha entrado em operação (WEFFORT, 1972).

Como combinar esse processo de judicialização, fundado em bases fortemente autoritárias, e aquele advindo do processo democrático dos anos 1988 será o propósito adiante. O fio condutor aqui será exatamente o processo de modernização brasileiro e a ideia de modernização da tradição, razão por que importa recuperar seus elementos locais.

\section{MODERNIZAÇÃO DA TRADIÇÃO: PROCESSO RADICALIZADO}

\footnotetext{
${ }^{12}$ A repercussão econômica dessa contenção sobre os salários é explorada por Santos (1973).
} 
Há uma importante e profunda relação entre o Direito e a modernidade ao ponto de ser percebido como uma das principais expressões da noção contemporânea de cidadania, como já apontado pela teoria social (DOMINGUES, 2002). Embora essa articulação já tenha sido sugerida acima, é importante explorar os elementos endógenos do processo de modernização brasileiro partindo da concepção de que modernização e tradição não são excludentes.

Nesse sentido, a observação de Domingues (DOMINGUES, 1998, p.213) acerca da modernidade merece registro:

\begin{abstract}
Deve-se evitar toma-la idealizadamente: ainda que o ocidente funcione como o nosso "outro" fundamental, foco de nossas identificações, a ocidentalização - um dos aspectos da modernização do mundo não ocidental, da "América Latina" e do Brasil em particular - é sempre uma ocidentalização específica, "real", onde certos "traços" são (mais ou menos intencionalmente) "selecionados “... Como processos, nem a modernização nem a ocidentalização devem ser reificadas.
\end{abstract}

O ingresso e o aprofundamento das instituições da modernidade no cenário brasileiro merecem ser compreendidos de forma concomitante, portanto, com o processo de modernização da tradição, ou seja, um processo de mudança dentro do qual a tradição procura adaptar-se ao mundo moderno desenvolvendo práticas e oferecendo argumentos sistemáticos em seu favor. Como processo, vale observar, não tem um sentido definido e está sujeita a elementos contingentes e mesmo seu impulso depende da ação de coletividades dominantes ou subordinadas (DOMINGUES, 1998).

Os anos 1930 no Brasil revelaram esse processo de transição sem rupturas e com o registro da preservação de certas caraterísticas da tradição, como o predomínio do agrarismo ou a incorporação seletiva de frações da população rural deslocada para as cidades e integrada seletivamente ao processo de industrialização e expansão da riqueza urbana. Esse movimento, sob controle das frações das elites hegemônicas, limitando os efeitos da pressão por maior liberdade e igualdade, restringia o campo de ação das organizações dos trabalhadores, como visto, com o recurso ao Direito e ao sistema judicial como ferramentas de ação destinadas a manter o curso do processo de incorporação seletiva ${ }^{13}$.

Como assinala Domingues (2004), o esgotamento desse processo de modernização sob controle ficaria evidente em 1988, quando as instituições com as quais a tradição operava foram democratizadas para dar passagem a uma realidade política que já não podia ser contida

\footnotetext{
${ }^{13}$ Esses limites ficam claros, por exemplo, na ideia de cidadania regulada (SANTOS, 1979).
} 
nos limites postos. Um relevante pluralismo societário foi paulatinamente ganhando dimensão.

Neste trabalho, questiona-se a validade ou não dessa formulação, ou seja, se a resposta a essa nova dinâmica social, mais plural, fundada em novas e diversificadas subjetividades coletivas, encontrou expressão no rearranjo institucional do processo constituinte dos anos 1980 ou o novo modelo procurou replicar a fórmula de controle da tradição, sob nova roupagem. Busca-se também compreender nesse registro a adequação do constitucionalismo democrático incorporado ao Direito brasileiro e a centralidade assumida pelo sistema judicial.

Se nas democracias centrais esse protagonismo resultou de algum consenso político em torno da afirmação de princípios e valores construídos a partir do ambiente social com alguma finalidade emancipatória ${ }^{14}$, o caso brasileiro, por outro lado, seria dependente, desde o início, da institucionalização do projeto inscrito na carta política de 1988. Nesse sentido, o sistema judicial, manobrando uma nova expertise construída em cenário distinto, assumiria uma das faces operacionais do pacto político garantindo o acesso à justiça e a ampliação dos próprios mecanismos de formação da vontade da nossa democracia plural, ainda por construir-se.

\section{O CONSTITUCIONALISMO DEMOCRÁTICO: NOVA EXPERTISE}

A Constituição de 1988 é a porta de entrada de uma nova expertise no cenário jurídico brasileiro, o chamado constitucionalismo democrático ou neoconstitucionalismo (BARROSO, 2005). Essa nova perspectiva teórica emergiu vencedora do processo constituinte com a inscrição de ferramentas destinadas a tornar efetivas as normas constitucionalizadas.

$\mathrm{O}$ inesperado sucesso das minorias parlamentares e dos juristas que a assessoravam conduziu a teoria jurídica a adotar novas formas de interpretação e de operação do sistema constitucional. Nesse sentido, o papel do intérprete foi acentuado no novo modelo com a incorporação da ideia de normas abertas, vazias de significado, destinadas a serem preenchidas conforme uma dinâmica interpretativa fortemente baseada no sistema de princípios integrado ao texto.

\footnotetext{
${ }^{14}$ Dentro do contexto de reconstrução europeu, vale reter.
} 
Essa concepção de Constituição Aberta, se um paralelo é possível com o processo de institucionalização do Direito do Trabalho brasileiro, é a porta de entrada da subjetividade no sistema jurídico brasileiro, dada a força irradiadora das normas constitucionais.

O que essa dinâmica sinaliza, portanto, é a centralidade do papel do intérprete nesse arranjo porque será sua a tarefa de dar sentido, legitimidade e principalmente, eficácia ao novo sistema normativo.

Por sinal, recuperando aquele momento fundacional, Cittadino (2004, p.14) destaca:

[...] o movimento de retorno ao direito no Brasil também pretende reencantar o mundo. Seja pela adoção do relativismo ético na busca do fundamento da ordem jurídica, seja pela defesa intransigente da efetivação do sistema de direitos constitucionalmente assegurados e do papel ativo do Judiciário, é no âmbito do constitucionalismo brasileiro que se pretende resgatar a força do direito.

Posta a tarefa, os anos seguintes experimentaram uma explosão da dogmática constitucional procurando institucionalizar essa nova expertise e conferir organicidade ao modelo ${ }^{15}$.

Assim, percebe-se que ao sistema de justiça foram canalizadas as expectativas normativas que o novo cenário democrático impunha e, para tanto, seus atores manobrariam com maiores doses de discricionariedade.

Como reafirma Barroso (2009, p.107-108), por seu caráter aberto, as normas constitucionais comportariam uma dose de variabilidade que acentuava o papel do intérprete na definição do seu sentido dentro do cenário de sua aplicação:

[...] as cláusulas constitucionais, por seu conteúdo aberto, principiológico e extremamente dependente da realidade subjacente, não se prestam ao sentido unívoco e objetivo que certa tradição exegética lhes pretende dar. O relato da norma, muitas vezes, demarca apenas uma moldura dentro da qual se desenham diferentes possibilidades interpretativas. À vista dos elementos do caso concreto, dos princípios a serem preservados e dos fins a serem realizados é que será determinado o sentido da norma, com vistas à produção da solução constitucionalmente adequada para o problema ser resolvido.

Entretanto, vale observar, que o risco de perversão desde sempre pairou sobre o desenho adotado, o que, por sinal já era assinalado pela teoria jurídica (CAPPELLETTI, 1993). Fundamentalmente, no caso brasileiro, porque a estratégia implicava a reformulação do sistema de pensamento jurídico de forma concomitante ao desafio de concretizar o novo

\footnotetext{
${ }^{15}$ Em Cittadino (2004) há um amplo inventário dessa expansão.
} 
sistema de direitos. Em paralelo, havia a necessidade de manter o equilíbrio diante dos riscos envolvidos na adoção de fórmulas interpretativas sujeitas aos subjetivismos de ocasião, capazes de comprometer a própria integridade do sistema jurídico.

Como colocam Nonet e Selznick (2010, p.124), esse conflito entre "integridade" e "abertura" do sistema jurídico e suas instituições é crucial:

O dilema não é exclusivo do direito: todas as instituições passam por um conflito entre "integridade" e "abertura". Há integridade quando uma instituição está fortemente comprometida com determinada missão ou pode ser responsabilizada por esta mediante controles externos. Contudo, instituições muito engajadas em determinadas missões geralmente acabam tão comprometidas com sua maneira de fazer e ver as coisas que perdem a sensibilidade ao ambiente social.

Numa síntese, os autores complementam o dilema:

Em outras palavras, responsabilidade gera formalismo e retraimento, torna as instituições mais rígidas e menos aptas a lidar com novas contingências. Por outro lado, abertura pressupõe grandes doses de discricionariedade, de modo que a ação dos órgãos institucionais possa manter-se flexível, adaptável e autocorretiva. Mas as reponsabilidades ficam mais vagas quando perdem precisão e surge o perigo de que os comprometimentos se diluam à medida que aumenta a flexibilidade. Em consequência, a abertura degenera em oportunismo, quer dizer, na adaptação incontrolada a acontecimentos e pressões.

Uma instituição responsiva, nesse contexto, seria aquela que estivesse apta a conservar sua capacidade de compreender o que é essencial à sua integridade e, ao mesmo tempo, levar em consideração as novas forças do ambiente social. Ou seja, sua capacidade de adaptação é responsável: percebe as pressões sociais como fontes de conhecimento e de oportunidades de autocorreção. Mas, "para assumir essa postura, a instituição precisa contar com a diretriz de uma finalidade" (NONET; SELZNICK, 2010, p.124).

Como se percebe, a tarefa comportava um enorme desafio institucional e uma profunda reformulação do sistema de pensamento jurídico capaz de aproximar a nova expertise da realidade cotidiana das relações sociais, ainda marcada pelo profundo quadro de desigualdade. Se a proposta que emergiu dos anos 1980 foi destinada ao enfrentamento desse cenário, como sugere o preâmbulo da Constituição de 1988, o caráter distributivo do sistema 
normativo seria dependente do desempenho do sistema de justiça brasileiro ${ }^{16}$, cuja centralidade já era anunciada.

\section{JUDICIALIZAÇÃO ONTEM E HOJE: JUSTIFICATIVAS E APROXIMAÇÕES}

Os anos 1990 em diante experimentaram uma enorme expansão da litigiosidade dentro do sistema judicial brasileiro, com a ampliação do volume de demandas. O sentido desse processo pode ser visto como uma realização daquela centralidade imaginada pelos constituintes dos anos 1980, tanto quanto pode revelar uma disfuncionalidade perturbadora da estratégia adotada, com a asfixia do sistema de justiça assolado pelo excesso de demandas ${ }^{17}$.

Independente das explicações desse fenômeno importa, sob o prisma analítico, verificar o quanto a proposta de integração do sistema judicial ao processo democrático e o protagonismo assumido desde então impactaram a realidade desigual do cenário brasileiro, face às promessas distributivas que animaram aquele pacto político.

Portanto, a questão é observar se a estratégia de canalização das expectativas ao Judiciário afetou de algum modo os crônicos problemas distributivos que marcaram nosso processo de modernização.

Nesse sentido, retomando o argumento dentro da chave da modernização da tradição, é importante observar como nossa imersão nessa tendência de escala mundial, a judicialização, seria uma resposta tanto aos dilemas das democracias ocidentais contemporâneas, como aos constrangimentos e adaptações do processo de democratização dos anos 1980.

Por outro lado, vale recuperar o fato de que o recurso ao sistema judicial como mecanismo eficiente de integração social já havia sido experimentado desde os anos 1930 no âmbito das relações de trabalho. Sua ampliação para dar conta de um projeto de integração social em larga escala não seria, assim, uma inovação, mas o contexto de complexificação, com novos e antigos problemas ainda por enfrentar dentro do processo de aprofundamento da modernidade brasileira ${ }^{18}$, impunha constrangimentos significativos.

\footnotetext{
${ }^{16}$ Utiliza-se a expressão sistema de justiça como marcador do papel das diversas instituições do Estado envolvidas nesse processo.

${ }^{17}$ Para melhor exploração desse cenário os bancos de dados do Conselho Nacional de Justiça - CNJ fornecem importantes subsídios, como revela a série de relatórios Justiça em Números. Disponível em: http://www.cnj.jus.br/ . Consulta em 12/02/2019.

${ }^{18}$ Por exemplo, a construção de novas subjetividades coletivas e a decantada desigualdade socioeconômica.
} 
Como visto, o cenário europeu pós-segunda guerra foi o ponto de partida dessa reformulação do papel do sistema judicial. Naquele momento, o desafio era assegurar a reconstrução do sistema político sob novas bases. O objetivo consistia em garantir, por um lado, a preservação dos direitos das minorias, o respeito a direitos básicos de qualquer indivíduo e, de outro, estimular o crescimento econômico agora sob fortes bases redistributivas ${ }^{19}$.

O modelo de Estado Social que emergiu, de alguma forma, respondeu a tais expectativas com um largo período de relativa estabilidade e crescimento econômico, equilíbrio na distribuição da riqueza, pelo menos até os anos 1980, quando uma nova agenda se impôs.

Essa breve recuperação da trajetória dos países centrais do ocidente, por certo, envolve dinâmicas de maior complexidade e não há intenção de reduzi-la a poucas linhas. Entretanto, um ponto relevante merece destaque. A recuperação do cenário de devastação dos anos 1940 exigiu uma reformulação do pacto político hegemônico e a incorporação de um componente redistributivo cujas expectativas alimentaram essa reordenação, particularmente europeia.

As chamadas e conhecidas ondas de direitos e pactos políticos, sociais, econômicos e culturais respondem a uma dinâmica não apenas retórica dos textos políticos, mas a uma efetiva ampliação dos canais de participação nos sistemas democráticos, tanto quanto a efetiva distribuição da renda e da riqueza sob novas bases.

Assim, a judicialização atendia a duas dinâmicas bem definidas: a ampliação do pacto político hegemônico e a redistribuição da riqueza socialmente produzida, combinação inconcebível dentro do modelo em vigor até a primeira metade do século $\mathrm{XX}^{20}$.

O caso brasileiro, sob inspiração desse processo e dos sistemas de pensamento que o moldaram, recupera, ainda que tardiamente, aquela trajetória, com o fortalecimento do sistema de justiça e a inscrição do papel distributivo nesse novo modelo forjado com a nova Constituição.

A judicialização emergia, assim, como corolário de uma renovada institucionalidade destinada a dar conta dos problemas relacionados ao déficit democrático do sistema político ${ }^{21}$.

\footnotetext{
${ }^{19}$ Como conceitos distintos na teoria econômica, aos meus propósitos, entretanto, os aspectos distributivos e redistributivos serão abordados de modo intercambiável.

${ }^{20}$ Ainda que a pressão por reformulação tenha sido a tônica dos embates que, ao final, resultaram nos conflitos de enormes proporções que marcaram aquele período.

${ }^{21}$ Tendo sido percebida aqui como alargamento do processo de participação e construção da vontade.
} 
Por outro lado, os Tribunais seriam, na sua operação cotidiana, uma das engrenagens destinadas a expandir o papel distributivo anunciado na Carta de 1988.

Desde já, pode-se entrever, assim, os potenciais limites dessa estratégia. Isso porque nos processos de judicialização das democracias centrais, a despeito da reorientação do papel do sistema judicial e do importante desempenho das suas Cortes Constitucionais, o peso da integração social ainda residia no sistema político e nas suas articulações com o ambiente social.

No modelo brasileiro, entretanto, o fortalecimento do sistema político e esse enraizamento na sociedade seriam tarefas do sistema judicial, não apenas como árbitro dos conflitos, mas também, e o que é mais problemático, expressando, traduzindo e construindo os valores que deveriam alimentar o pacto democrático ${ }^{22}$.

Esse aspecto central do constitucionalismo brasileiro não passou despercebido, por exemplo, por Cittadino (2004) dentro de sua análise sobre os problemas da incorporação de concepções comunitaristas no texto de 1988. Isso porque o desenho institucional imaginado pressupunha a existência de valores compartilhados por nossa comunidade abstraindo o cenário concreto de profundas divisões sociais que caracterizam nossa sociedade.

Para dar conta desse déficit, a efetividade normativa da Constituição seria dependente de uma cidadania juridicamente ativa, participativa, capaz de mobilizar o sistema judicial através dos procedimentos inscritos no texto constitucional e construir algum tipo de consenso cívico numa sociedade marcada por profundas divisões. Nesse sentido, a atuação do Poder Judiciário, permeável e capaz de compreender essa dinâmica, seria fundamental (CITTADINO, 2004).

A questão, portanto, é perceber até que ponto esse desenho institucional, com seus desafios e imperfeições teóricas, poderia dar conta do papel integrador que lhe estava sendo atribuído.

Aqui, a experiência acumulada do recurso ao sistema judicial no campo das relações de trabalho, o que se tem chamado judicialização das relações de trabalho, no cenário da modernização da tradição poderia ter algum valor explicativo quanto aos rumos do processo de judicialização contemporâneo.

Vale reter que isso não implica ignorar a importância da Constituição de 1988 como um marco na abertura do sistema político e uma tentativa de inscrição de um projeto de

\footnotetext{
${ }^{22}$ Por sinal o ativismo que daí emergiu revelou-se um enorme complicador.
} 
construção de uma ordem social mais inclusiva. O ponto, contudo, é observar como teria sido replicada a tendência de transformação com preservação e o papel instrumental do sistema judicial para dar conta dessa tarefa, caraterísticas marcantes do processo de modernização brasileiro.

Como demonstrado, o processo de modernização brasileiro pode ser inserido na chave da modernização da tradição, quando as forças hegemônicas adaptaram suas práticas e reformularam o pacto de integração social, em favor da preservação de seus próprios interesses. Seria esse o sentido do pacto político vitorioso que emergiu da fase antecedente do agrarismo.

Numa limitada síntese, a solução de compromisso intraelites que se seguiu permitiu o avanço e o dinamismo da economia à custa da industrialização sob a condução do Estado e o controle das pressões dos trabalhadores por melhoria das suas condições de existência e maior participação política. No plano social o estímulo a migração e a urbanização ${ }^{23}$ ocorreriam de modo concomitante com a incorporação dos trabalhadores, sob a tutela do Estado, já impondo limites ao seu aprofundamento. O Direito seria funcional nessa dinâmica e uma renovada expertise foi construída e institucionalizada no campo das relações de trabalho vertendo os eventuais conflitos para o sistema judicial, sinalizando como a face da contenção seria sua tarefa singular. O papel da Justiça Especializada do Trabalho seria crucial aqui ${ }^{24}$.

Os anos 1980, contudo, revelaram os limites desse arranjo institucional. Nesse sentido, a preservação do processo de modernização exigia uma reformulação do pacto político hegemônico, agora pressionado pela ampliação da participação, dentro do cenário de uma sociedade ainda profundamente marcada pela desigualdade social, apesar do enorme dinamismo econômico. O processo de modernização teria encontrado seu caminho nesse

${ }^{23} \mathrm{O}$ processo de urbanização é acentuado e a taxa correspondente parte de 31,24\% em 1940 até alcançar 84,36\%, em 2010. Disponível em: https://seriesestatisticas.ibge.gov.br/series.aspx?vcodigo=POP122\&t=taxa-urbanizacao. Consulta em 13/01/2020.

${ }^{24}$ Análise desse movimento de contenção através do recurso ao sistema judicial fica evidente em Santos (1973), especialmente quanto ao salário mínimo real e aos julgamentos de dissídios coletivos que versavam sobre o tema do salário profissional que, em suma, atuavam no sentido da contenção da expansão dos ganhos dos trabalhadores. Não custa recordar aqui a forte expansão do PIB brasileiro desde 1946 até a derrocada do milagre econômico nos anos 1970. Disponível em: https://agenciadenoticias.ibge.gov.br/...mediaibge/.../7531a821326941965f1483c85ca. Consulta em 14/01/2020. 
ambiente aparentemente hostil, mas seu aprofundamento exigia novas soluções que preservassem, ainda que parcialmente, os interesses hegemônicos ${ }^{25}$.

A solução, como sustentado acima, curiosamente, envolveu uma dinâmica em torno da apropriação de uma renovada expertise do campo jurídico, o chamado constitucionalismo democrático, e a versão dos conflitos para o sistema judicial ao qual caberia sua solução, tanto quanto a efetivação dos valores e princípios que guiariam o pacto político.

Nesse cenário, seria singular perceber como foram manobradas as expectativas e os mecanismos institucionais em favor de alguma forma de autopreservação desses interesses hegemônicos, o que validaria a judicialização como uma estratégia ampliada de contenção do ângulo distributivo do projeto constitucional.

De fato, se os anos 1988 testemunharam o expurgo dos elementos autoritários que organizavam o sistema político, importa compreender o quanto a subsequente desorganização da política institucional e a expansão do papel do sistema judicial teriam contribuído para esse sentido do avanço com preservação.

Um paralelo singular de reafirmação dessa estratégia ficou expresso nas contradições do próprio texto aprovado, como sinalizam as soluções de compromisso em torno de pontos sensíveis, tais como, por exemplo, o imposto sobre grandes fortunas, delegado eternamente à legislação complementar ou mesmo a manutenção da unicidade e do imposto sindical, pilares da estrutura laboral herdada do período Vargas ${ }^{26}$.

Vale observar que, da perspectiva organizacional do sistema democrático e sua efetividade, os temas subjacentes a tais arranjos são centrais: partidos políticos, tributação e estrutura sindical.

A persistência da desigualdade socioeconômica ${ }^{27}$ desponta, assim, como a evidência mais significativa do quanto o papel distributivo atribuído ao sistema de justiça encontrou seus limites nesse ambiente adverso, apesar da enorme mobilização por direitos canalizada para o sistema judicial.

\footnotetext{
${ }^{25}$ Interesses de elites políticas e econômicas dentro de um quadro geral de fragmentação e construção de subjetividades coletivas característicos da modernidade.

${ }^{26}$ Por sinal, a liberdade sindical é um dos pilares do fortalecimento das entidades sindicais, cuja ação eficaz tem forte papel indutor no equilíbrio da distribuição da riqueza.

${ }^{27}$ Mesmo quando considerado um indicador social bastante utilizado pela literatura, como o coeficiente de GINI, o quadro revela a mesma tendência de distribuição desigual, ainda que algumas oscilações positivas possam ser observadas em séries históricas, como a produzida pelo IPEA (1976-2014). Disponível em http://www.ipeadata.gov.br/Default.aspx. Consulta: 20/01/2020.
} 
Dessa forma, as expectativas da teoria jurídica em torno do papel atribuído ao sistema judicial, ao menos nos moldes delineados pelo constitucionalismo democrático dos anos 1980, parecem não se confirmar ${ }^{28}$. Por outro lado, vale observar como replicar a estratégia dos anos 1930 e reforçar o papel integrador do Judiciário brasileiro faria pouco sentido num ambiente de aprofundamento da modernidade, com suas dinâmicas de maior complexificação dos processos de interação social.

Nesse contexto de avanço, com conservação do quadro de desigualdade socioeconômica, a categoria da modernização da tradição tem forte valor explicativo para melhor compreensão da dinâmica que emergiu a partir de 1988, como apontado até aqui. No próximo tópico, como conclusão, o argumento será sintetizado.

\section{CONCLUSÃO}

Após longo período de arbítrio e restrições ao exercício das liberdades civis e políticas, a retomada democrática brasileira dos anos 1980 não desprezou a necessidade de um vasto catálogo de direitos para dar conta de um déficit acumulado, pelo menos desde o rompimento institucional dos anos 1960. Por outro lado, o ideal distributivo, inserido na concepção de justiça social, seria a resposta e a promessa aos desequilíbrios socioeconômicos que, desde sempre, ameaçaram a estabilidade do sistema republicano brasileiro.

Nesse sentido, as expectativas que emergiram desse momento fundacional passaram a ter como um dos rumos o enfrentamento das desigualdades, expressão que alcançava não apenas as já conhecidas, como a renda e a riqueza, mas incorporava as novas agendas de uma sociedade complexa e moderna, como as de gênero, cor ou etnia, por exemplo. O leque de demandas já revela a enormidade dos desafios postos ao renovado sistema político.

Uma das estratégias para lidar com esse desafio pelos constituintes foi 0 reposicionamento do sistema judicial dentro do modelo institucional que organizaria o novo pacto político. Com o recurso às experiências acumuladas pelos países centrais do ocidente entrou em cena o sistema jurídico acompanhado por uma nova expertise, o constitucionalismo democrático, destinada a instrumentalizar esse novo papel atribuído ao sistema judicial. Essa

\footnotetext{
${ }^{28}$ Por sinal, a literatura jurídica já assinala, ainda de forma assistemática, esse problema de materialização do pacto constitucional e já vem identificando o sentido de autopreservação dessa dinâmica, especialmente na América Latina. Nesse sentido, são sugestivas as indagações de Gargarella (2013) sobre esse processo de materialização e seus limites. Sobre a importância e a eficiência do desenho institucional adotado em cartas políticas ver Chilton e Versteeg (2014).
} 
nova dinâmica induzia uma ação mais ativa apoiada em novas ferramentas, por vezes redesenhadas, como no caso da ação civil pública. Portanto, esse maior protagonismo foi imaginado e seria estratégico para dar efetividade ao projeto inscrito na Constituição.

Como demonstrado, esse caminho já replicava de algum modo o momento fundacional do processo de modernização brasileiro dos anos 1930. Isso se explica porque a estratégia destinada a dar suporte ao modelo hegemônico de então, autoritário num primeiro momento, foi justamente pela via do Direito do Trabalho e suas instituições, como forma eficiente para enfrentar a questão social e seu potencial disruptivo dos sistemas de ordem.

Essa proposta envolveu a articulação entre o desenvolvimento econômico à custa da contenção dos enfrentamentos abertos no mercado de trabalho. O papel do sistema judicial trabalhista seria crucial nesse momento porque esse conflito seria vertido para dentro das estruturas do Estado e, sob o manto da neutralidade da expertise jurídica e dos procedimentos judiciais, a contenção ocorreria na prática. Com a restauração democrática dos anos 1940 esse modelo passaria a ter efeitos práticos, o que revela sua funcionalidade mesmo quando aberto o sistema da ordem à participação política de novos atores.

A judicialização das relações de trabalho traz, portanto, esse registro de compatibilidade com o sistema de democracia política tanto quanto de rebaixamento das tensões próprias aos interesses conflitantes no mercado de trabalho.

O resultado desse arranjo foi o forte impulso econômico experimentado pelo Brasil com a preservação do cenário de desigualdades socioeconômicas.

O que os anos 1980 retratam?

Se uma síntese dessa inflexão política é possível, o período de estagnação econômica a partir dos anos 1980 deixou claros os limites do pacto que sustentava o modelo hegemônico. Pressionado por constrangimentos internos e externos, o novo arranjo envolveu a adoção da expertise do constitucionalismo democrático e seu recheado catálogo de direitos, mas preservando elementos organizacionais e estruturais relevantes especialmente quanto aos temas sensíveis, como tributação, sistema político e estrutura sindical. O sistema judicial surge então como elemento estabilizador desse pacto e a ele passam a ser direcionadas toda sorte de demandas, ao ponto de gerar uma sobrecarga com o potencial imobilizador de sua própria atividade jurisdicional.

A expansão do sistema judicial ao longo dos últimos trinta e dois anos reproduziu, por esse ângulo, a dinâmica da modernização da tradição, esse movimento de adaptação que, já nos anos 1930, percebeu como o recurso ao Direito e suas instituições poderia ser funcional 
ao sentido de autopreservação dos interesses hegemônicos. Ainda que a admissão de novos atores e agendas tenha sido uma marca do constitucionalismo democrático brasileiro, há evidências, como acima desenvolvidas, de que o ideal genuíno de construção de uma ordem justa e inclusiva encontrou seus limites nesse arranjo, manobrado dentro do processo de modernização brasileiro.

Entretanto, o caso brasileiro desvenda uma dinâmica interna particular quando incorporada a perspectiva da judicialização das relações de trabalho, justamente por revelar como a adaptação venceu o potencial inovador do processo constituinte dos anos 1980. O desafio persiste e o sistema democrático é hoje pressionado por enfrentar o que pode ser chamado de nova questão social, ainda sem propostas de inovação institucional significativas.

No conturbado cenário contemporâneo, está posta a relevância da imaginação institucional que animou o projeto constituinte para dar conta dessa complexa dinâmica. De toda sorte, passados mais de trinta e dois anos desde a publicação da Constituição Cidadã, seria o caso de questionar-se o quanto o impulso transformador foi superado por meras adaptações contingentes.

\section{REFERÊNCIAS BIBLIOGRÁFICAS}

ARANTES, Rogério Bastos. Judiciário e Política no Brasil. São Paulo: Editora Sumaré/Educ, 1997.

ARANTES, Rogério Bastos; KERCHE, Fábio. Judiciário e democracia no Brasil. São Paulo: Novos Estudos, nº 58, p.11-26, jul. 1999.

BARROSO, Luís Roberto. Interpretação e Aplicação da Constituição. São Paulo: Editora Saraiva, $7^{\mathrm{a}} \mathrm{Ed}, 2009$.

BARROSO, Luís Roberto. Neoconstitucionalismo e constitucionalização do direito: o triunfo tardio do direito constitucional no Brasil. Jus Navigandi, Teresina, ano 10, n. 851, 1 nov. 2005. Disponível em <http://jus.com.br/artigos/7547>.

CAPPELLETTI, Mauro. Juízes Legisladores?. Porto Alegre: Sérgio Antônio Fabris Editor, 1993.

CAPPELLETTI, Mauro; GARTH, Bryant. Acesso à justiça. Porto Alegre: Sérgio Antônio Fabris Editor, 1988.

CARDOSO, Adalberto Moreira. A década neoliberal e a crise dos sindicatos no Brasil. São Paulo: Boitempo Editorial, 2003. 
CITTADINO, Gisele. Pluralismo, direito e justiça distributiva: elementos da filosofia constitucional contemporânea. Rio de Janeiro: Lumen Juris, 2004.

CHILTON, Adam S. e VERSTEEG, Mila, "Do Constitutional Rights Make a

Difference?". Coase-Sandor Institute for Law \& Economics .Working Paper No. 694, 2014.

Disponível em: http://papers.ssrn.com/sol3/papers.cfm?abstract_id=2477530.

DELGADO, Maurício Godinho. Curso de Direito do Trabalho. $15^{a}$.ed. São Paulo: LTr, 2016.

DOMINGUES, José Maurício. Modernidade, tradição e reflexividade no Brasil

contemporâneo. Tempo Social; Rev. Sociol. USP. São Paulo, p. 209-234,1998.

DOMINGUES, José Maurício. Interpretando a Modernidade - imaginário e instituições. Rio de Janeiro: Editora FGV, 2002.

DOMINGUES, José Maurício. Ensaios de Sociologia - Teoria e Pesquisa. Belo Horizonte: Editora UFMG, 2004.

GARGARELLA, Roberto. Latin american constitutionalism,1810-2010: the engine room of the Constitution. Oxford: Oxford University Press, 2013.

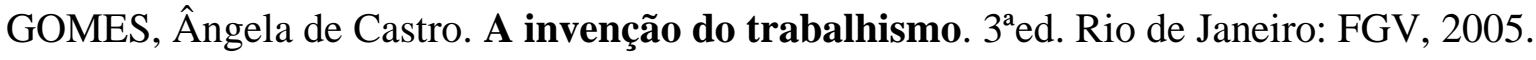

HABERMAS, Jünger. Direito e democracia: entre facticidade e validade. v. 1, 2. ed.

Tradução de Flávio Beno Siebeneichler. Rio de Janeiro: Tempo Brasileiro, 2003

LAFER, Celso. A reconstrução dos direitos humanos. São Paulo: Cia das Letras, 1999.

MACIEL, Débora Alves; KOERNER, Andrei. Sentidos da Judicialização da política: duas análises. São Paulo: Lua Nova. n. 57, p.113-133, 2002.

NONET, Philippe; SELZNICK, Philip. Direito e Sociedade: a transição ao sistema jurídico responsivo, Rio de Janeiro: Editora Revan Ltda, 2010.

NORONHA, Eduardo G. O Modelo Legislado das Relações de Trabalho no Brasil. Dados Revista de Ciências Sociais, v.43, n. 2, 2000. DOI: http://dx.doi.org/10.1590/S001152582000000200002 . Acesso em 17/05/2019.

SANTOS, Roberto Araújo de Oliveira. Leis Sociais e Custo da Mão-de-Obra no Brasil. São Paulo: LTr Editora Ltda. e Ed. da Universidade de São Paulo,1973.

SANTOS, Wanderley Guilherme dos. Cidadania e Justiça. Rio de Janeiro: Campus. 1979.

TATE, C. Neal; VALLINDER. Torb jorn (Org.). The Global Expansion of Judicial Power. New York/London: New York University Press, 1995.

WEFFORT, Francisco. Sindicatos e política. Tese (Livre Docência) Faculdade de Filosofia, Letras e Ciências Humanas, Universidade de São Paulo, São Paulo,1972. 
WERNECK VIANNA, Luiz. Liberalismo e sindicato no Brasil. Belo Horizonte: Editora UFMG, 1978.

WERNECK VIANNA, Luiz. Esquerda brasileira e tradição republicana - estudos de conjuntura sobre a era FHC-Lula. Rio de Janeiro: Revan, 2006.

WERNECK VIANNA, Luiz; CARVALHO, Maria Alice Rezende de; MELO, Manuel Palácios Cunha; BURGOS, Marcelo Baumann. Judicialização da política e das relações sociais no Brasil. Rio de Janeiro: Revan, 1999.

WERNECK VIANNA, Luiz; BURGOS, Marcelo Baumann. Revolução processual do direito e democracia progressiva. In: WERNECK VIANNA, coord. A Democracia e os três poderes no Brasil. Belo Horizonte: Editora UFMG, 2002.

Submissão em 02/03/2020 / Aceito em 23/03/2021 